\title{
THE APPLICATION OF A POSITIVE END-EXPIRATORY PRESSURE PLATEAU TO THE BIRD VENTILATOR
}

\author{
F.R.H. WRIGLEY, M.B., B.S., F.R.C.P.(C) ${ }^{\bullet}$
}

Persistent hypoxaems may be present in certain patients in spite of treatment with 100 per cent oxygen on a ventilator. The application of a positive end-expiratory pressure plateau to the ventilator cycle can, in certain of these patients, produce dramatic improvement. ${ }^{1}$ Most reported series have used volume-cycled ventilators to achieve this end. Attempts to apply an expiratory pressure plateau to the Bird Mark 7 ventilator has in the past proved unsuccessful. As the expiratory pressure is applied the ventilator either slows down or ceases to cycle completely. This appears to be due to the inability of the cycling mechanism to overcome the positive pressure present in the ventilator-patient circuit. ${ }^{2}$ This positive pressure exists throughout the system from the expiratory valve back through the humidifier and into the patient side of the ventilator. The expiratory retard cap supplied with the Bird ventilator does not produce an end-expiratory pressure plateau but merely slows expiration. It does not raise the functional residual capacity, which appears to be the important factor in the successful use of a positive end-expiratory pressure ptateau. ${ }^{\mathrm{p}}$

This paper describes a means used to overcome the difficulty, utilizing readily available equipment.

Two additional standard Bird expiratory valves are required (Figure 1). Valve $A$ in Figure 1 has the diaphragm compartment open to the atmosphere. It is inserted in such a manner that gases attempting to retum from the patient to the ventilator during the expiratory phase are obstructed, but pass freely to the patient during inspiration. The second expiratory valve ( $B$ in Figure 1 ) is inserted between the ventilator and the non-return valve $(A)$. It serves to return the pressure in the ventilator to atmospheric during expiration, but is pressurized to close during inspiration by connecting it in series with the patient's expiratory valve. It will thus be seen that positive pressure can be held in the patient circuit during expiration while pressure in the ventilator returns to atmospheric. The automatic cycling mechanism will then function normally. It is, of course, not possible for the patient to trigger the ventilator and therefore the system is applicable only when it is desired to apply controlled ventilation. In Figure 1 the positive endexpiratory pressure is applied by leading the expired gases through a hose to vent underwater. Figure 2 shows a Bird ventilator adapted as described.

Normally, the patient will be attached to the ventilator by tracheostomy or endotracheal tube, but in a cooperative patient it is possible to use this machine with the adaptation described, by face mask and automatic cycling.

A refinement can be added in the form of a pressure gauge as shown ( $D$ in Figure 1) to denote the positive pressure present in the patient circuit. The valves can be placed nearer to the patient but they will then be moistened by the humidi-

-Associate Professor of Anaesthesia, Memorial University of Newfoundland. 


\section{METHOD OF APPLYING P.E.P.P. TO BIRD RESPIRATOR}

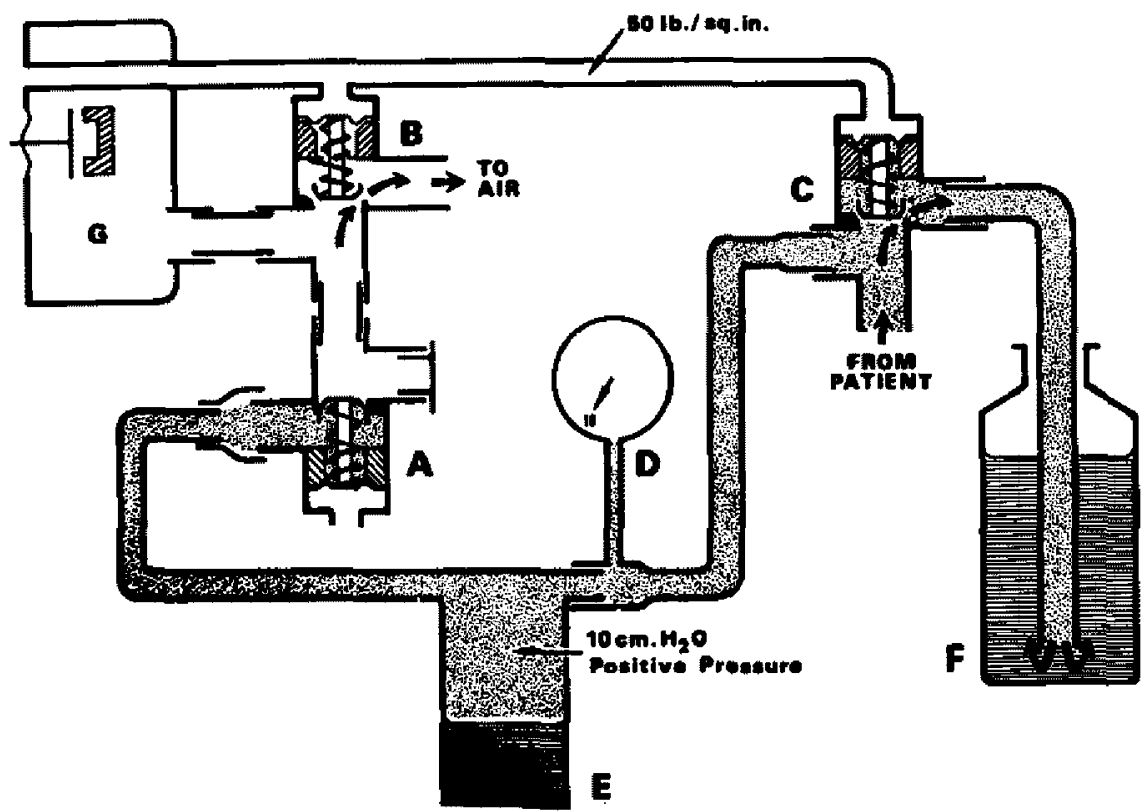

Figure 1. Bird Mark 7 ventilator shown during expiration with positive end-expiratory pressure plateau applied.

A. Bird expiratory valve acting as non-return valve.

B. Bird expiratory valve returning pressure in ventilator to atmospheric.

c. Patient's expiratory valve.

D. Pressure gauge.

E. Humidifier.

F. Expiratory gases venting underwater.

c. Bird ventilator.

fied gases and malfunction will be more likely to occur in this situation. At the time of preparing this communication the system has been utilized without mechanical difficulty in four cases.

\section{SUMMARY}

The Bird ventilator normally fails to cycle if an atternpt is made to add a positive end-expiratory pressure plateau. A simple means to adapt the ventilator is described. The method is simple and utilizes readily available spare parts.

\section{ACKNOWLEDGMENT}

I wish to record my thanks to the members of the Inhalation Therapy Department of St. John's General Hospital for their assistance in assembling the apparatus.

\section{RǴromÉ}

Un plateau de pression positive expiratoire ne peut être appliqué par le Bird parce qu'il interfère avec son mécanisme de déclanchement. Pour résoudre ce 


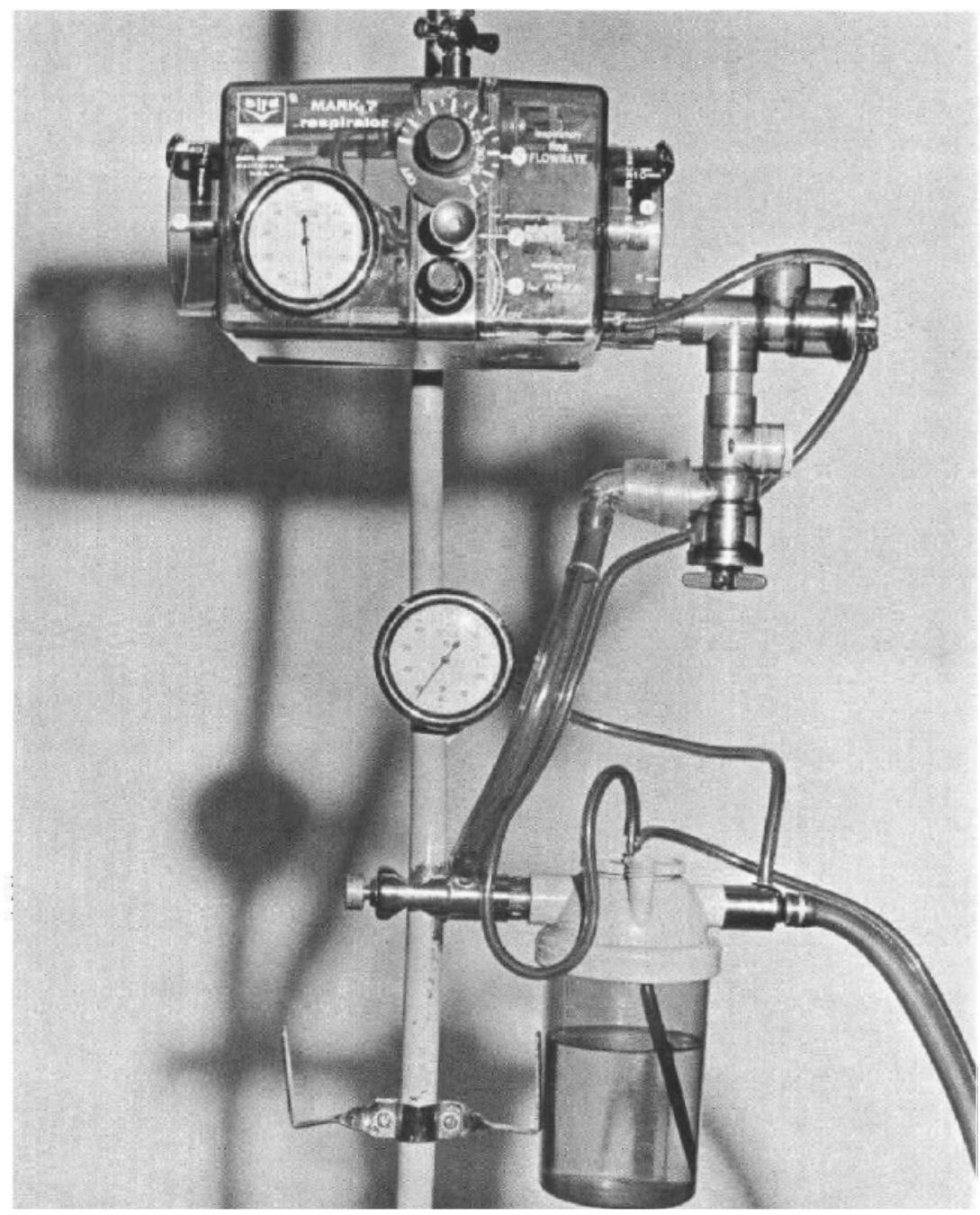

Frgure 2. Bird ventilator adapted to apply positive end-expiratory pressure plateau.

problème, il faut que la pression du respirateur retourne à la pression atmosphérique pendant que la pression positive expiratoire est appliquée au malade. Ceci peut se réaliser en attachant deux valves expiratoires au circuit tel quillustré dans les schémas.

\section{REFERENCES}

1. Ashraugh, D.G., Bigelow, D.B., Petry, T.L., \& Levine, B.E. Acute respiratory distress in adults. Lancet, 2: 319 (1967).

2. Davizs, D.W. The effect of adding a positive expiratory pressure plateau (P.E.P.P.) with controlled ventilation with a Bird Mark 7 or Mark 8 ventilator. Cdn. Anaes. Soc. Jour. 19: 217 (May 1972).

3. McIntYre, R.W., Laws, A.K., \& Ramachandran, P.R. Positive expiratory pressure plateau: Improved gas exchange during mechanical ventilation. Canad. Anaesth. Soc. J. 16: 477 (1969). 